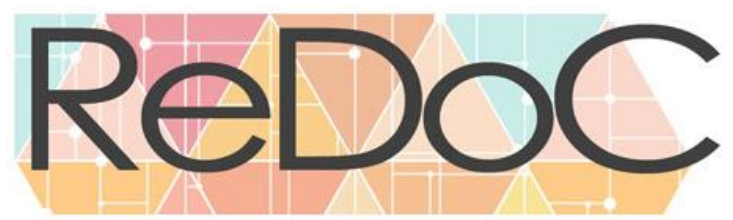

Revista Docência e Cibercultura

\title{
INCLUSÃO DIGITAL NAS ESCOLAS: CAMINHOS POSSÍVEIS PARA SE (RE)PENSAR O DITAL EM REDE NA PRÁTICA PEDAGÓGICA
}

\author{
DIGITAL INCLUSION IN SCHOOLS: POSSIBLE WAYS TO (RE)THINK \\ DIGITAL NETWORK IN PEDAGOGICAL PRATICE
}
INCLUSIÓN DIGITAL EN LAS ESCUELAS: CAMINOS POSIBLES PARA (RE)PENSAR LO DIGITAL EN LA PRÁCTICA PEDAGÓGICA

Viviane Aparecida Tomaz Polate ${ }^{1}$

\begin{abstract}
Resumo: Este trabalho monográfico tem como objetivo investigar as potencialidades de ensinar-aprender engendradas pelos usos das tecnologias digitais no cotidiano escolar. Por meio de pesquisa bibliográfica foram traçados possíveis caminhos para se (re)pensar o digital em rede na prática pedagógica, de forma a se refletir sobre seu papel mediador nos processos educacionais. Para isso, buscou-se considerar a importância dos aspectos metodológicos no trabalho com os conhecimentos, da familiarização do professor com o digital em rede e do quanto a instituição de ensino está preparada para receber esta nova geração de alunos que convivem no seu dia a dia com essas novas tecnologias.
\end{abstract}

Palavras-chave: Inclusão digital, educação, tecnologias, ensino.

\begin{abstract}
This monographic work aims to investigate the potential of teaching-learning engendered by the uses of digital technologies in daily school life. Through bibliographical research, possible paths were developed to (re)think the digital network in pedagogical practice, in order to reflect on its mediating role in educational processes. The purpose of this study was to consider the importance of methodological aspects in working with knowledge, the familiarization of the teacher with the digital network, and the extent to which the educational institution is prepared to receive this new generation of students who live in their daily lives with these new technologies.
\end{abstract}

Key words: Digital inclusion, education, technologies, teaching.

Resumén: Este trabajo monográfico tiene por objetivo investigar las posibilidades de enseñar-aprender estimuladas por los usos de las tecnologías digitales en el cotidiano

Submetido em: 04/04/2018 - Aceito em: 27/04/2018 - Publicado em: 29/06/2018.

${ }^{1}$ Universidade Federal do Estado do Rio de Janeiro (UNIRIO). E-mail: vivipolate@gmail.com 


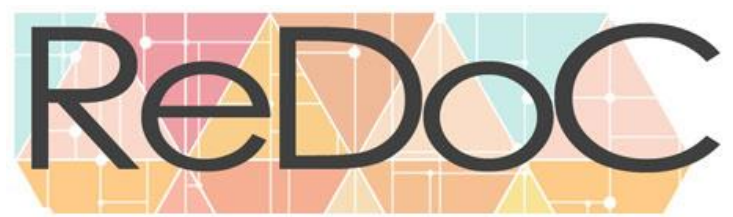

Revista Docência e Cibercultura

escolar. Por medio de la investigación bibliográfica fueran trazados posibles caminos para (re)pensar lo digital en rede en la práctica pedagógica. Para esto, se buscó considerar la importancia de los aspectos metodológicos en el trabajo con los conocimientos, la familiarización del profesor con lo digital en red y como la institución escolar está preparada para recibir esta nueva generación de alumnos que conviven en su día a día con estas nuevas tecnologías.

Palabras clave: Inclusión digital, educación, tecnologías, enseñanza.

\section{INTRODUÇÃO}

Atualmente vivemos em um mundo onde as tecnologias cada vez mais se popularizam no cotidiano escolar, com a presença de inúmeros recursos tecnológicos sendo comumente utilizados tanto pelos alunos quanto pelos professores. Neste contexto, vale citar a televisão, Datashow, computadores, aparelhos celulares, smartphones e tablets. Dito isso, não há como negar que vivemos em uma época em que as tecnologias de massa e digitais vêm cada vez mais mediando os processos de ensinar-aprender nos diversos espaços educativos.

Como ex-aluna da rede estadual do município de Mimoso do Sul (Espírito Santo/ES), pude presenciar a instalação dos laboratórios de informática que são uma realidade já há alguns anos nas instituições de ensino daquele município. Entretanto, pude presenciar diariamente a dificuldade que alguns professores encontravam em se apropriar dos recursos tecnológicos digitais nas suas aulas, muitos por ainda não conseguirem se socializar com as tecnologias digitais, outros por demostrarem desinteresse em aprender como manusear tais artefatos culturais ou até mesmo por desacreditar que tais recursos contribuiriam para o desenvolvimento educacional de seus alunos. Assim, como ex-aluna de escola pública neste município, percebia a resistência de muitos professores em contribuir para a promoção da inclusão digital em nossas escolas, fato que acabava privando os alunos de interagirem com as tecnologias digitais. Os processos de ensinoaprendizagem calcados no que Paulo Freire (2013) denomina de educação bancária ainda eram uma das características mais marcantes na educação de nosso município. 


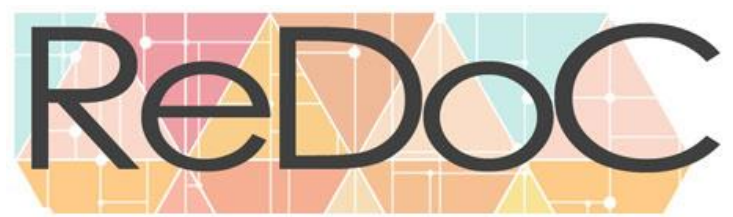

\section{Revista Docência e Cibercultura}

Habitamos em um mundo que nos convida constantemente a interagir com recursos tecnológicos, fazendo com que a inclusão digital seja uma possibilidade também no cotidiano escolar. Entretanto, vale ressaltar que ainda é possível observar professores que apresentam dificuldades com o manuseio das tecnologias em suas aulas (COUTO JUNIOR, 2013). Sobre isso, podemos atribuir como causas a nítida escassez de recurso público tanto para a formação continuada de professores voltada para (re)pensar os usos das tecnologias nos processos educacionais quanto para a implementação das tecnologias digitais na rede pública de ensino do país.

Hoje as escolas do município de Mimoso do Sul encontram-se com um bom aparato tecnológico, pouco utilizado pela maioria dos professores das escolas municipais e estaduais, que não conseguem manusear com destreza aparelhos como Datashow, computador e notebook, que já se tornaram comuns no meio escolar. Muitos desses professores ainda se restringem a utilizar equipamentos como DVD player, televisão e micro-system (aparelho de som), deixando de lado outras tecnologias mais recentes que poderiam também contribuir para explorar novos conhecimentos em sala de aula. Esse cenário me remete para os dizeres de Pretto (2002), para quem evidencia grande preocupação para o fato de que muitas "escolas passam a ser equipadas com essas chamadas novas tecnologias, mas o sistema educacional, em última instância, permanece o mesmo" (p. 124).

A partir de minhas experiências como ex-aluna nas escolas da rede estadual do município de Mimoso do Sul, percebo que mesmo possuindo laboratórios de informáticas nas escolas, ainda hoje a inclusão digital é uma realidade não concretizada. Conforme já mencionado, muitos professores continuam ancorados na perspectiva da educação bancária, que prima pela mera transmissão de conhecimento ao colocar em prática processos de ensinar-aprender unidirecionais (FREIRE, 2013). Esse tipo de educação dificulta a inserção de seus alunos no meio digital, impedindo que outras práticas pedagógicas emerjam através das inúmeras oportunidades de interação que esses recursos tecnológicos digitais podem oferecer no espaço educacional. 


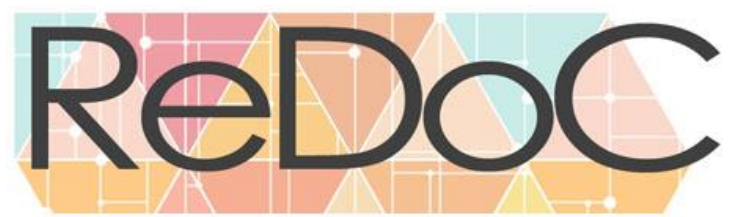

Revista Docência e Cibercultura

A discussão aqui levantada sobre os desafios da inclusão digital no ambiente escolar configura-se como sendo de grande valia para o desenvolvimento de meu trabalho como aluna e, futuramente, como professora. Pesquisar esse tema me traz elementos teóricos importantes para (re)pensar minhas metodologias de trabalho a partir do contexto sociocultural dos alunos, permitindo inúmeras reflexões sobre o papel mediador das tecnologias digitais em rede nos processos de ensino-aprendizagem. Desse modo, o objetivo deste trabalho é investigar as potencialidades de ensinar-aprender engendradas pelos usos das tecnologias digitais no cotidiano escolar.

O tipo de pesquisa utilizada para a elaboração do trabalho é a bibliográfica analítica. Dessa forma, me apropriei principalmente da contribuição de autores que investigam a relação dos sujeitos com as tecnologias, buscando trazer para o campo da educação uma discussão necessária e urgente abarcando o tema da inclusão digital na prática pedagógica.

\section{TECNOLOGIAS DIGITAIS NO COTIDIANO ESCOLAR}

A partir do século $\mathrm{XX}$, diversas inovações tecnológicas começaram a povoar o cotidiano das pessoas, entre elas vale citar o telefone, o cinema, o rádio, as revistas e a televisão. Tais inovações, mesmo com seu surgimento antecedendo o século XXI, continuando sofrendo inúmeras transformações e aperfeiçoamentos. Diversas tecnologias mais antigas hoje constituem-se enquanto artefatos culturais de última geração ao incorporar outros avanços tecnológicos mais recentes, como é o caso dos aparelhos de telefonia celular conectados à rede mundial de computadores. Tais tecnologias foram vinculadas ao nosso cotidiano estabelecendo uma íntima relação com o consumismo ditado por um mundo extremamente capitalista.

A partir da década de 1980, o avanço tecnológico impulsionado por uma onda de consumismo se fez presente em vários setores da vida social, chegando também a interferir na educação oferecida pelas escolas, sejam estas públicas ou privadas. A invasão

\begin{tabular}{l|l|l|l|l|l|l|} 
(C) Redoc & Rio de Janeiro & v.2 & n.2 & p. 121 & Maio/Agosto. 2018 & ISSN 2594-9004
\end{tabular}




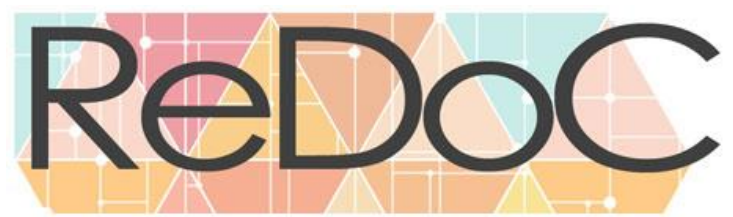

\section{Revista Docência e Cibercultura}

do mundo tecnológico se faz visível na vida do homem em vários instantes: no interior de sua casa, na rua e nas salas de aulas, nas diversões, no trabalho, ou seja, a vida em sociedade hoje é cada vez mais mediada pela relação que estabelecemos com as tecnologias. Assim, a relação estabelecida com as pessoas através dos usos dos aparelhos tecnológicos modifica nosso modo de pensar, agir, sentir e produzir conhecimento. Pretto e Assis (2008) caminham nessa direção e ressaltam que "a apropriação da cultura digital passa a ser fundamental [nesse contexto], uma vez que ela já indica intrinsecamente um processo crescente de reorganização das relações sociais mediadas pelas tecnologias digitais, afetando em maior ou menor escala todos os aspectos da ação humana" (p. 78).

Bergmann (2010), além disso, ressalta a importância de se conseguir inserir essas tecnologias no contexto escolar, fazendo com que o professor consiga unir conhecimento, informação e, consequentemente, promover novas estratégias metodológicas mediadas pelos usos das tecnologias digitais com a intenção de favorecer a inclusão digital na sala de aula. De acordo com Lima (2005), a inclusão digital vai muito além da utilização de tecnologias em sala e se constitui uma forma de inclusão social e justiça, dando a oportunidade para que muitos alunos estejam em contato com tecnologias que nem sempre encontram-se presentes em seus cotidianos familiares. Dessa forma, pode-se afirmar que a inclusão digital nas escolas não é apenas o mero acesso e utilização dessas tecnologias, mas uma estratégia importante para que estudantes e professores busquem, de forma colaborativa, amplia seus conhecimentos através de novos sentidos a serem produzidos com os usos dessas tecnologias no cotidiano da vida social.

A inclusão digital é uma possibilidade em nosso cotidiano educacional. Não há como fechar os olhos para a grande gama de aparatos tecnológicos com os quais interagimos nos mais diversos ambientes da vida cotidiana. Dito isso, a educação necessita propor novos horizontes para seus discentes, estimulá-los a pensar a respeito de novas perspectivas metodológicas de aprender-ensinar. O professor precisa estar disposto a construir, com seus alunos, estratégias metodológicas que possibilitem favorecer a construção de novas formas de produzir conhecimento. Desse modo, pode-se afirmar que: 


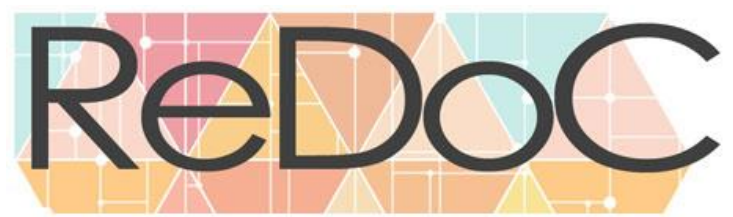

Revista Docência e Cibercultura

A educação está diante de um desafio: inserir as novas tecnologias da informação e comunicação na escola com vistas a promover a alfabetização tecnológica, a democratizar o acesso às tecnologias da informação e comunicação para alunos e comunidade, e, consequentemente, para a melhoria da qualidade do ensino. Para tanto, não é suficiente investir apenas na infraestrutura física, com a criação de laboratórios de informáticas nas escolas e a compra de equipamentos sofisticados, se não se investir na formação dos professores, formação do educador para operá-los e saber utilizá-los com finalidades educativas (BERGMANN, 2010, p. 2).

Não basta que as instituições educacionais sejam equipadas com aparatos tecnológicos capazes de fazer com que haja interseção entre a aprendizagem e tais equipamentos. Isso porque presenciamos diariamente em nossas escolas o fato de que nem sempre tais tecnologias conseguem ser utilizadas por todos os professores devido à falta de conhecimento técnico. Fazer com que todos estejam conectados e dispostos a interagir é um desafio porque, tradicionalmente, a educação bancária (FREIRE, 2013) ainda precisa ser rompida para favorecer uma maior participação dos estudantes nos processos de ensino-aprendizagem. Dessa forma, esse trabalho monográfico defende a criação de metodologias inovadoras que possam abarcar o uso das tecnologias digitais em rede na prática pedagógica com o objetivo de que sejam exploradas novas formas de se entrar em contato com os conhecimentos. Para isso, concordo que uma sociedade conectada

Necessita de uma educação que contemple processos virtuais, educação em rede ou hipertextual e a criatividade, elementos que caracterizam o aleatório, o imprevisível e o complexo. As tecnologias em rede compreendem processos não lineares, abertos e descontínuos, apresentando a informação como um mosaico que pode propiciar a construção de conhecimento pessoal e coletivo (BERGMANN, 2010, p. 9). 


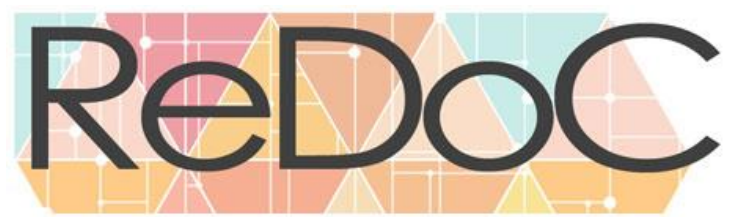

\section{Revista Docência e Cibercultura}

Vivendo em uma sociedade globalizada, constantemente rodeada por inovações tecnológicas, saber adequar o uso dessas tecnologias em sala pode possibilitar ao professor rever conceitos e práticas educacionais que possibilitem levar seu aluno a interagir com o conhecimento em tempo real auxiliando-o também na construção de um saber que esteja sintonizado com seu contexto sociocultural. Para (re)pensar a educação na sociedade do conhecimento é imprescindível reconhecer o importante papel das Tecnologias da Informação e Comunicação (TICs) na construção de uma sociedade na qual a inclusão e a justiça social sejam prioridades (LIMA, 2005).

Diante da conectividade que aflora em nossa sociedade, torna-se cada vez mais necessário que o professor abra os olhos para todo o aparato tecnológico que cerca a realidade de seu aluno. Isso constitui um aspecto importante na promoção de um fazer pedagógico que valorize a inclusão digital e que reconheça o papel mediador dos aparelhos digitais na produção de conhecimento. Dito isso, concordo com Lima (2005), que argumenta:

Considerando que o acesso às tecnologias de informação e comunicação não contempla toda a sociedade torna-se necessário criar estratégias que propicie o acesso de forma universal, ou seja, abranger e promover de forma democrática a inclusão digital e a capacitação para a utilização dessas tecnologias de acordo com a necessidade do indivíduo (p. 41).

No processo de inclusão digital as escolas constituem-se como sendo um dos espaços mais democráticos para a implementação de políticas públicas direcionadas para o acesso aos meios digitais. Quando esse acesso é oferecido cabe aos professores a função de mediar o conhecimento e a inclusão digital democrática a partir da inserção em sua prática pedagógica de ações simples como, por exemplo, a utilização dos laboratórios de informática e outros recursos tecnológicos A discussão sobre a presença e a inserção das tecnologias de informação e comunicação que fazem uso da internet no processo 


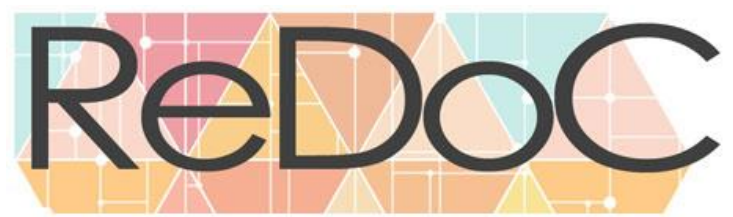

\section{Revista Docência e Cibercultura}

educacional é atualizada permanentemente por autores que se debruçam sobre o tema (KENSKI, 2003, 2007; MELARE; OKADA; KENSKI, 2012).

Os trabalhos até aqui mencionados caminham numa direção que defende (re)pensar o uso das tecnologias na sala de aula, entretanto, nenhum deles defende uma única forma de incorporar as tecnologias na prática pedagógica. Esta pesquisa tampouco almeja buscar um caminho único na forma como o digital em rede pode ser (re)pensado na produção de conhecimento, uma vez que não defendo um manual de "como fazer". Dito isso, busco traçar possíveis possibilidades metodológicas inventivas que partam das experiências sociais dos praticantes culturais (estudantes e seus professores).

Não se pode negar que nas últimas décadas alunos e professores sofreram a influência das tecnologias digitais no cotidiano escolar. Embora a prática docente em sua grande maioria ainda esteja alicerçada pelo modelo tradicionalista, o qual busca uma perfeição alcançada pela repetição e pelo pensamento linear racional, as inserções de aparatos culturais digitais trazem a oportunidade para que o professor (re)pense sua própria prática dentro da sala de aula.

A escola atual vive um momento de extrema contradição entre o modelo de ensino adotado e as práticas culturais de seus estudantes e professores (MARTINS; COUTO JUNIOR, 2007; NÓVOA, 1999), e isso requer a necessidade de que as metodologias sejam revistas. A escola deve não somente qualificar os estudantes para o mercado de trabalho, mas também para vida ao promover novas práticas sociais cidadãs, críticas e dialógicas que sejam potentes na transformação do mundo. Frente a isso, desconsiderar os usos das tecnologias na produção de conhecimento em sala de aula é negar a possibilidade de que os alunos explorem outras linguagens que vêm cada vez mais fazendo parte da experiência humana. Neste contexto, vale relembrar o argumento de Petarnella (2008) sobre a existência de uma tensão no interior da escola. De acordo com o autor, há uma contradição entre a experiência cotidiana no uso das tecnologias digitais, presentes nas várias atividades corriqueiras do dia a dia, e a experiência com essas tecnologias na prática pedagógica. Nem sempre as experiências dentro do espaço escolar 


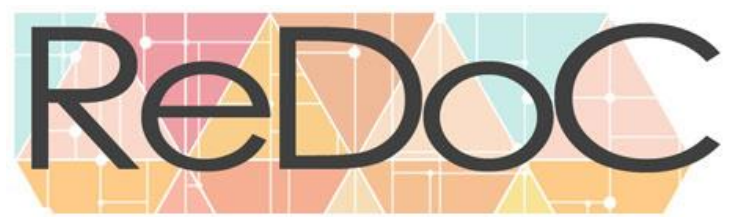

Revista Docência e Cibercultura

se constituem de forma dinâmica e viva quanto aquelas vivenciadas pelos usuários nos diversos espaços físicos fora da escola (PETARNELLA, 2008).

No entanto, cabe ainda reforçar que o mero uso das tecnologias digitais dentro do ambiente escolar não garante que os processos de ensinos-aprendizagem sejam mais dinâmicos e atraentes. Isso porque não basta que a escola adquira recursos tecnológicos e materiais pedagógicos considerados "modernos", a questão central é tornar a prática pedagógica significativa para todos aqueles envolvidos na produção de conhecimento. Neste contexto é extremante importante que haja uma percepção por parte do professor de que na educação sempre há a necessidade em se traçar novas concepções pedagógicas a partir da influência do uso dos novos recursos tecnológicos que visam possibilitar novas oportunidades de aprendizado ao aluno. A perspectiva educacional baseada na transmissão de conhecimentos pode muito bem ser utilizada também a partir do uso do digital em rede, de forma semelhante àquela metodologia maçante das chamadas "aulas tradicionais", cuja exposição/explicação insere o professor no centro dos processos educacionais. Diante da necessidade de ressignificar a prática pedagógica, Santos (2002) argumenta que "podemos nos inspirar no digital e nos seus desdobramentos (hipertexto, interatividade, simulação), propondo práticas curriculares mais comunicativas, com mais e melhores autorias individuais e coletivas" (p. 115).Com isso, é importante problematizar as práticas educacionais a fim de encontrar caminhos metodológicos alternativos que possam ser potentes para incentivar a participação dos estudantes em processos de ensino-aprendizagem melhor sintonizados com seus interesses e anseios.

As diversidades de linguagens utilizadas nas práticas sociais propiciam aos professores a oportunidade para que as atividades de ensino incorporem diferentes formas de se entrar em contato com o conhecimento. Com isso, precisamos visar a melhora da qualidade dos processos de ensino-aprendizagem através do uso de imagens, vídeos, sons etc capazes de potencializar ainda mais o trabalho com as informações em sala, tornando mais prazerosa e dinâmica a produção de conhecimento.

Os Parâmetros Curriculares Nacionais (PCNs) (BRASIL, 2000) afirmam que 


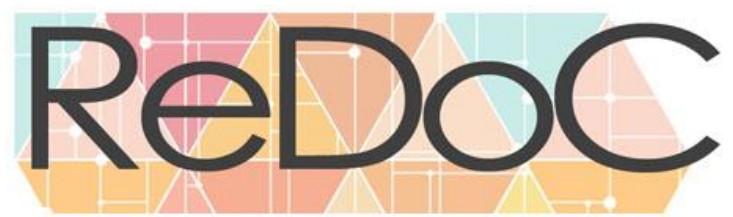

Revista Docência e Cibercultura

As novas tecnologias da comunicação e da informação permeiam o cotidiano, independente do espaço físico, e criam necessidades de vida e convivência que precisam ser analisadas no espaço escolar. A televisão, o rádio, as informáticas, entre outras, fizeram com que os homens se aproximassem por imagens e sons de mundos antes inimagináveis. (...) Os sistemas tecnológicos, na sociedade contemporânea, fazem parte do mundo produtivo e da prática social de todos os cidadãos, exercendo um poder de onipresença, uma vez que criam formas de organização e transformação de processos e procedimentos (p. 11-12).

A evolução social ocorre devido a um amplo e complexo conjunto de fatores, dentre os quais estão os usos do digital em rede. A sociedade atual é reconhecida por muitos como "Sociedade da Informação", a qual possui como uma de suas características a presença das chamadas novas tecnologias em praticamente todas as atividades da vida cotidiana. Viana (2004) é enfático a afirmar que:

\begin{abstract}
Vivencia uma realidade em que as crianças nascem e crescem manuseando as tecnologias que estão ao seu alcance. (...) A era da informação é fruto do avanço das novas tecnologias que estocam, de forma prática, o conhecimento e gigantescos volumes de informações. (...). Estas novas tecnologias permitem-nos acessar não apenas conhecimentos transmitidos por palavras, mas também por imagens, sons, vídeos, dentre outros (p. 11-12).
\end{abstract}

Não há como negar que a utilização de equipamentos tecnológicos está cada dia mais presente no cotidiano de nossas crianças. Fechar os olhos para essa realidade é desconsiderar as infâncias que vêm sendo vivenciadas por crianças que exploram cada vez mais o mundo através das tecnologias digitais2. Frente a isso, a sociedade contemporânea exige a necessidade de que o conhecimento seja constantemente

\footnotetext{
${ }^{2}$ Foge ao foco deste trabalho discutir a relação das crianças com as tecnologias. Para isso, ver os trabalhos de Girardello e Campos (2013), Alcântara e Osório (2014) e Couto Junior (2013).
}

\begin{tabular}{l|l|l|l|l|l|l|} 
(C) Redoc & Rio de Janeiro & v.2 & n.2 & p. 127 & Maio/Agosto. 2018 & ISSN 2594-9004
\end{tabular}




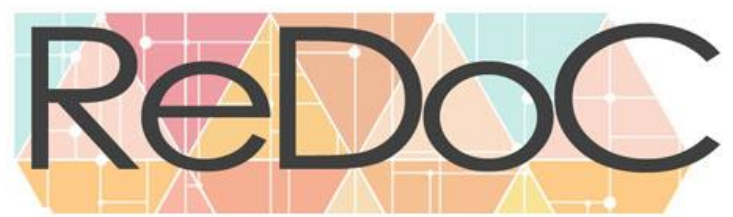

Revista Docência e Cibercultura

(re)elaborado e, consequentemente, exige que a escola esteja atenta à (re)avaliação constante de suas estratégias de ensino-aprendizagem.

\section{O PAPEL DO PROFESSOR FRENTE AO USO DA TECNOLOGIA}

Ainda nos bancos escolares, quando os futuros professores estão em formação, são disponibilizados inúmeros conhecimentos teóricos os quais visam direcioná-los para sua prática docente, tanto no campo didático quanto teórico voltado (ou não ao mundo tecnológico). Porém, mesmo dotados de uma boa parte teórica, a realidade das salas de aula muitas das vezes perpassam os conhecimentos anteriormente adquiridos, sendo necessário traçar estratégias metodológicas que estejam sintonizadas com o contexto sociocultural dos alunos. Freire (2003), sobre a entrada no docente no seu primeiro dia de trabalho, mostra que "dificilmente este primeiro dia estará isento de inseguranças, de timidez ou inibições" (p. 66). Sensações como insegurança norteiam o mundo docente na busca por metodologias que os possibilitem trabalhar os conhecimentos com os alunos de modo a atender as expectativas do sistema educacional e de toda a comunidade escolar. O manuseio de recursos tecnológicos nem sempre faz parte do cotidiano docente e, muitas das vezes, não condiz com a realidade de muitos professores e alunos.

Apesar da realidade sociocultural da instituição educacional, em muitas situações, demandar a construção de inovações metodológicas, sabe-se que nem sempre é tarefa fácil concretizar mudanças significativas na prática pedagógica. Outro ponto que deve ser observado refere-se à falta de experiência de muitos professores ao lidar com os recursos tecnológicos. Tal dificuldade pode ser encontrada tanto entre os professores iniciantes quanto entre os mais antigos, sendo necessário ao professor mudar sua postura frente às novidades tecnológicas, buscando atribuir novos sentidos ao digital em rede nas práticas pedagógicas. Produzir sentido significa olhar para o digital em rede como parte significativa das relações humanas e, consequentemente, da forma como muitos sujeitos vêm produzindo conhecimento na contemporaneidade. 


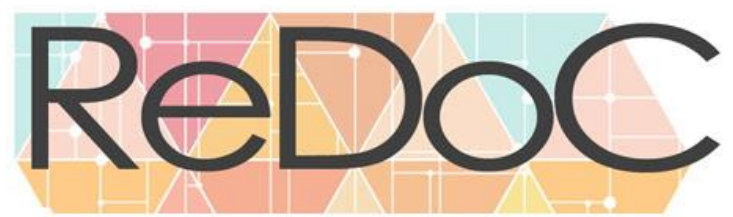

\section{Revista Docência e Cibercultura}

Com a popularização das tecnologias em rede, emerge um desafio para muitos professores no que se refere à capacidade de propor novas atividades de aprendizagem utilizando-se das chamadas novas tecnologias. Colocar em prática tais atividades nem sempre trazem segurança ao professor, mas que são necessárias para que esta seja capaz de propor a seus alunos novos caminhos na produção de conhecimento.

Em meio a tantos recursos tecnológico disponibilizados pelas instituições de ensino (mesmo as públicas em nosso município), o uso das tecnologias pode representar ao professor um desafio constante. Os estudantes podem se constituir como verdadeiros parceiros na tarefa de encorajar que seus professores aprendam cada vez mais e melhor a se apropriar das tecnologias digitais. Isso é o Couto Junior (2013) reitera na pesquisa realizada com professoras da educação infantil, ao afirmar que é preciso "descobrir, junto às crianças, formas de utilizar as diversas linguagens das diversas tecnologias, permitindo que os professores rediscutam e reflitam sobre suas próprias práticas pedagógicas numa era marcada pela cultural digital" (p. 142).

Para Peña (s/d):

O desafio que se impõe hoje aos professores é reconhecer que os novos meios de comunicação e linguagens presentes na sociedade devem fazer parte da sala de aula, não como dispositivos tecnológicos que imprimem certa modernização ao ensino, mas sim conhecer a potencialidade e a contribuição que as TICs podem trazer ao ensino como recurso e apoio pedagógico às aulas presenciais e ambientes de aprendizagem no ensino a distância (p. 10).

Não é possível que o professor ignore a presença das tecnologias, porém há de se ter o cuidado para que haja a concepção de que não se trata de substituir pelo "novo" tudo o que já vem sendo trabalhado pelos professores. Concordo que seja preciso adequar-se a essa contemporaneidade que nos cerca, vislumbrando o mundo de possibilidades que estes recursos podem trazer no contexto das dinâmicas de ensinar-aprender. Novamente reforço aqui que não é mais possível ignorar a importância das tecnologias digitais em rede na prática de produção de saber. Considero necessário que o professor esteja 


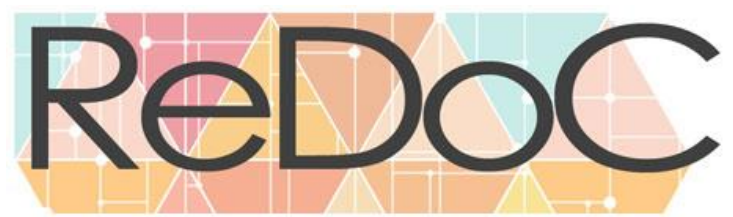

\title{
Revista Docência e Cibercultura
}

disponível para conhecer as inúmeras transformações sociais engendradas pelo digital, atentando-se para a velocidade com que as informações da "sociedade em rede" são produzidas e compartilhadas através dos diferentes meios de comunicação. Com isso, o aluno conseguirá adquirir conhecimentos significativos com o objetivo de enriquecer seu conhecimento.

$\mathrm{Na}$ sociedade atual, a qual traz como uma de suas características marcante a diversidade de linguagens, resultado da constante inserção dos mais variados meios de comunicação, vimos a cada dia o uso de meios midiáticos no cotidiano de nossos alunos, incluindo jogos, mensagem de multimídias, filmes, entre outros. Ao conseguir prover a inserção dessas tecnologias no ambiente escolar buscando a adaptação dessas práticas, tem-se a melhoria da qualidade do ensino ofertado, todavia, cabe reiterar que a presença das tecnologias no ambiente escolar por si só não garante a qualidade no ensino. Inúmeras são as possibilidades metodológicas a serem utilizadas na sala de aula com o uso das tecnologias digitais, e isso inclui a utilização de imagens, jogos, músicas, vídeos, dentre outras linguagens que poderiam aproximar-se ainda mais das experiências sociais dos estudantes.

\begin{abstract}
As novas tecnologias da comunicação e da informação permeiam o cotidiano, independente do espaço físico, e criam necessidades de vida e convivência que precisam ser analisadas no espaço escolar. A televisão, o rádio, as informáticas, entre outras, fizeram com que os homens se aproximassem por imagens e sons de mundos antes inimagináveis. (...) Os sistemas tecnológicos, na sociedade contemporânea, fazem parte do mundo produtivo e da prática social de todos os cidadãos, exercendo um poder de onipresença, uma vez que criam formas de organização e transformação de processos e procedimentos (PCN's, 2000, p. 11-12).
\end{abstract}

Hoje não existe um local ideal para que a aprendizagem aconteça e sim lugares onde o conhecimento pode se fazer presente respeitando o tempo e a individualidade de cada aluno. Para isso, o professor necessita estar atento a essas possibilidades fazendo com que recurso tecnológicos como filmes, músicas, informações obtidas em sites, entre outros, não caiam na perspectiva da mera "transmissão de conhecimento, esvaziando de 


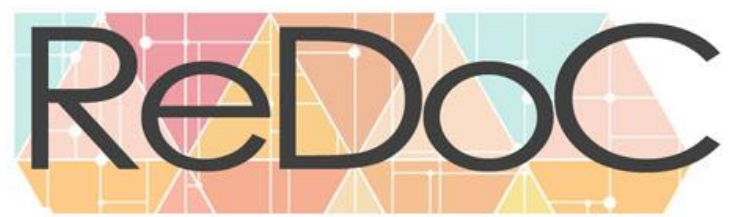

\section{Revista Docência e Cibercultura}

sentido as práticas educativas no cotidiano escolar. Cabe ao professor, uma vez inserido no contexto das práticas sociais mediadas pelas tecnologias digitais, conscientizar-se de que o trabalho desenvolvido utilizando recursos tecnológicos como filmes e imagens, por exemplo, quando bem desenvolvido, pode ser verdadeiramente instigante e produtivo para o aprendizado de seu aluno. Adotar estratégias metodológicas em sala de aula abarcando esses recursos poderia se constituir como um verdadeiro estímulo para que os estudantes percorram caminhos onde a exploração e a investigação de informações possam ir além daquelas tradicionalmente trabalhadas nos livros didáticos impressos. Dito isso, conseguir aliar as tecnologias como mediadoras do processo de ensinoaprendizagem ainda se configura como sendo um grande desafio para os professores, ainda mais para aqueles que atuam em redes públicas de ensino que, em geral, carecem de recursos públicos para que as salas de aula sejam devidamente informatizadas.

Outra consideração importante a ser feita refere-se à adequação do uso das tecnologias com a realidade dos alunos, o que demanda certos critérios a serem escolhidos pelo professor para que os recursos digitais possam ser explorados de forma dinâmica e prazerosa na sala de aula.

Os profissionais do campo da educação vêm reconhecendo a necessidade de buscar constantemente novas estratégias metodologias para atender à necessidade e a curiosidade dos alunos. Esses profissionais estão permanentemente confrontados com inovações tecnológicas que lhes possibilitam (re)pensar a própria prática pedagógica na medida em que (re)inventam seus modos de trabalhar os conhecimentos com os alunos.

O professor atual já se conscientizou de que são necessárias novas competências e atitudes para que o processo ensino-aprendizagem seja significativo para seu aluno e que consiga a responder a seus objetivos anteriormente traçados. Assim na escola, a prática pedagógica com a utilização das diversas tecnologias precisa realizar-se de maneira crítica para compreender, propor e desenvolver as estratégias de construção do conhecimento, e democrática para que esteja a serviço de uma educação preocupada com a mudança na sociedade, pretendendo a democratização dos saberes e das mídias. Portanto, o objetivo principal da prática pedagógica deve ser a ampliação do saber dos educandos, 


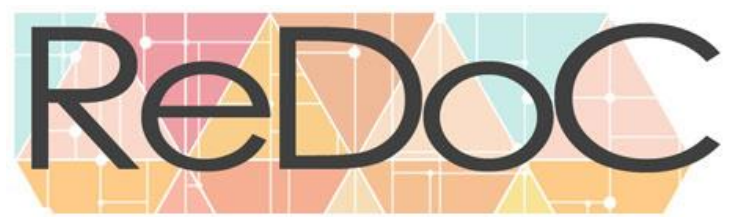

\section{Revista Docência e Cibercultura}

utilizando-se de todos os meios tecnológicos de informação e comunicação (CARVALHO, 2007, p. 20).

Ao professor ainda cabe a preocupação de levar para dentro de sala os recursos que não só sejam voltadas para estimular a aprendizagem, mas que também estes sejam compreensíveis e sirvam para trazer a interação e a democratização da aprendizagem.

Para além do pessimismo que ainda ronda o ambiente escolar onde a figura tradicional do professor muitas vezes sobrevive em meio a toda essa "invasão" tecnológica, observa-se que o mundo atual se mostra, a cada instante, mais aberto a explorar a produção de conhecimento a partir de simples clique. Entretanto, é cada vez mais desafiante pensar em inovações metodológicas na prática pedagógica quando a escola atual ainda é regida por tempos e espaços pré-determinados, ignorando, resistindo ou apresentando dificuldades para incorporar em seu cotidiano as inovações tecnológicas do nosso tempo.

\section{CONSIDERAÇÕES FINAIS}

Muito além de um simples aparato tecnológico, o uso de aparelhos eletrônicos como televisão, DVD player, Datashow, computadores, aparelhos celulares e tantos outros estão a cada dia "invadindo" não só nossas atividades cotidianas, mas também o ambiente escolar. Tal "invasão" surge em meio a uma disseminação de valores de comunicação permitindo que a cada instante o homem consiga estar conectado a uma cadeia de informação em tempo real possibilitando interagir, conhecer e aprender de forma colaborativa.

Assim, ao buscar discutir nesta pesquisa sobre as potencialidades de ensinaraprender engendradas pelos usos das tecnologias digitais no cotidiano escolar, pude perceber que, mesmo com todos os desafios, essas tecnologias vêm sendo exploradas nos processos educacionais. Muitos profissionais da educação já conseguiram inserir as 


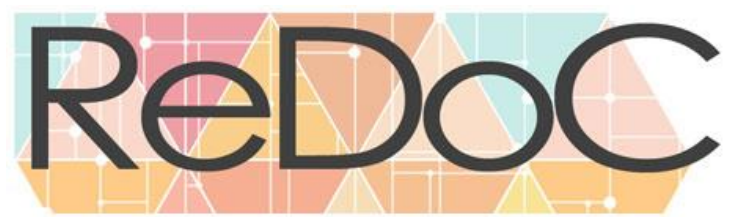

\section{Revista Docência e Cibercultura}

tecnologias digitais em seu cotidiano, possibilitando a construção de processos de ensinoaprendizagem mais dinâmicos e significativos.

Muito embora ainda possamos encontrar professores resistentes à introdução das TICs em sala de aula, seja por não saber manuseá-las ou por não acreditarem nas vantagens que seu uso pode proporcionar às aprendizagens de seus alunos, são notórios os avanços que muitos professores têm obtido ao levar para dentro de seu planejamento metodologias inovadoras mediadas pelo digital em rede.

Enfim, pude concluir que a inclusão digital nas escolas é uma necessidade que requer concretização. Para isso, não podemos ignorar a importância da formação de professores e das políticas públicas neste processo. Esse processo vai muito além da mera “implementação do digital” no cotidiano educacional, mas também requer investimento público para propiciar aos educadores a qualificação profissional necessária para atender aos desafios do tempo presente.

\section{REFERÊNCIAS}

ALCÂNTARA, Alessandra; OSÓRIO, António. Um caso lúdico: brincar no Facebook! In: PORTO, Cristiane; SANTOS, Edméa (Orgs.). Facebook e educação: publicar, curtir, compartilhar. Paraíba: EDUEPB, 2014, p. 113-129.

BERGMANN, Helenice. Maria Barcellos Escola e inclusão digital: desafios na formação de redes de saberes e fazeres. 2010, p. 2. Disponível em: http://www.abed.org.br/revistacientifica/Revista PDF Doc/2010/2010 19520101734 24.pdf. Acesso em: 03 de set. de 2016.

BRASIL. MEC - Ministério da Educação; Parâmetros Curriculares Nacionais - Ensino Médio; Brasília: MEC/Secretaria de Educação Básica, 2000. Disponível em: http://tcconline.utp.br/wp-content/uploads/2012/04/O-USO-DA-TECNOLOGIA-EMSALA-DE-AULA.pdf. Acesso em: 12 de jun. de 2017. 


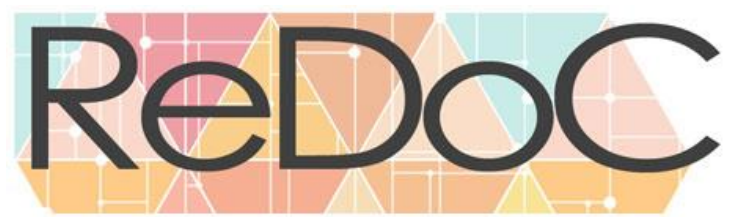

Revista Docência e Cibercultura

CARVAlHO, Rosiani. As Tecnologias No Cotidiano Escolar: Possibilidades De Articular O

Trabalho Pedagógico Aos Recursos Tecnológicos. Paraná, 2007.

COUTO JUNIOR, Dilton Ribeiro. Mídias e educação infantil: desafios na prática pedagógica.

Informática na Educação: teoria \& prática, Porto Alegre, v. 16, n. 2, p. 131-146, jul./dez. 2013.

FREIRE, Paulo. Pedagogia do Oprimido. 54ª edição. Rio de Janeiro: Paz e Terra, 2013.

FREIRE, Paulo. Professora sim, tia não: cartas a quem ousa ensinar. São Paulo, Olho D'Água, 2003.

GIRARDELLO, Gilka; CAMPOS, Karin Cozer. A produção narrativa das crianças no contexto das mídias. Comunicação \& educação, São Paulo, ano XVIII, n. 2, p. 107-113, jul./dez. 2013.

KENSKI, V. M. Tecnologias e ensino presencial e a distância. 2 ed. Campinas: Papirus, 2003.

KENSKI, V. M.. Educação e tecnologias: o novo ritmo da informação. Campinas: Editora Papirus. 2007.

LIMA, Presleyson Plínio de. A importância da inclusão digital no processo de inserção social e educacional através da utilização do software livre. Contagem / MG: Pontifícia Universidade Católica de Minas Gerais, 2005. 58f.

MARTINS, Daniele M.; COUTO JUNIOR, Dilton Ribeiro. Jovens jogadores de videogames e produção de sentidos: contribuições para se pensar práticas educativas alteritárias. In: REUNIÃO ANUAL INTERNACIONAL DA ASSOCIAÇÃO NACIONAL DE PÓSGRADUAÇÃO E PESQUISA EM EDUCAÇÃO: PESQUISA E COMPROMISSO SOCIAL, 30., 2007, Caxambu. Anais. . . Timbaúba: Espaço Livre, 2007. p. 1-6.

MELARE, D. ; OKADA, A. ; KENSKI, Vani Moreira. Coletividade aberta de pesquisa: os estilos de coaprendizagem no cenário online. Educação, Formação Tecnologias, v. 5, p. 1124, 2012.

NÓVOA, António. Os professores na virada do milênio: do excesso dos discursos à pobreza das práticas. Educação e Pesquisa, São Paulo, v. 25, n. 1, p. 11-20, jun. 1999. 


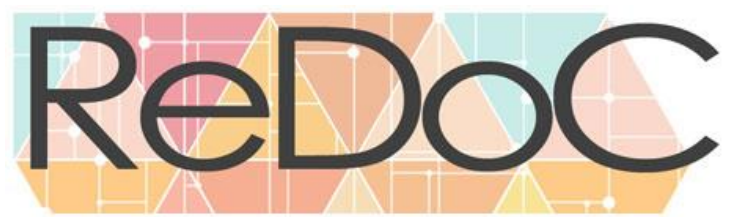

\section{Revista Docência e Cibercultura}

PEÑA, Maria De Los Dolores Jimenes. Ambientes de aprendizagem virtual: O desafio á prática docentes. S/D.

PETARNELLA, L. Sincretismo cultural e anacronismo escolar: o cotidiano de alunos e professores frente às TMDICS. $31^{\circ}$ Reunião Anual da ANPEd: Caxambu, 2008.

PRETTO, Nelson De Luca. Formação de professores exige rede! Revista Brasileira de Educação, São Paulo, v. 20, n. 20, p. 121-131, maio/jun./jul./ago., 2002.

PRETTO, Nelson De Luca; ASSIS, Alessandra. Cultural digital e educação: redes já! In: PRETTO, Nelson De Luca; SILVEIRA, Sérgio Amadeu (Orgs.). Além das redes de colaboração: internet, diversidade cultural e tecnologias do poder. Salvador: EDUFBA, 2008, p. 75-83.

SANTOS, Edméa. Formação de professores e cibercultura: novas práticas curriculares na educação presencial e a distância. Revista da FAEEBA - Educação e Contemporaneidade, Salvador, v. 11, n. 17, p. 113-122, jan./jun. 2002.

VIANA, M. A. P. Internet na Educação: Novas formas de aprender, necessidades e competências no fazer pedagógico. In: MERCADO, L. P. L. (Org.) Tendências na utilização das tecnologias da informação e comunicação na educação. Maceió: EDUFAL, 2004. 